Article available at nttp://Www.parasite-journal.org or nttp://dx.dol.org/10.1051/parasite/200108s2095

\title{
Present status of trichinellosis in Yugoslavia: Serbia
}

\author{
CUPERLOVIC K.*, DJORDJEVIC M.**, PAVLOVIC S.** \& SOFRONIC-MILOSAVLJEVIC L.*
}

\section{Summary :}

Trichinellosis was recognized almost one century ago as a health and animal husbandry problem in Serbia. In the last 10 years, trichinellosis has been expanding from three endemic regions (Srem, Macva and Negotinska Krajina) to neighbouring regions. The infection rate detected by veterinary inspection in 1999 year was $0.17 \%$ in slaughtered swines. Simultaneously, the number of infected humans increased three-five times in comparison with the period 1980-1990. For instance, 555 individuals were registered in 1999 as infected after the consummation of non-inspected pork from domestic swine or wild boar. Prevalence of trichinellosis in wild animals was examined more than a 20 years ago. The trichinellosis in horses has not been detected in the country, but infected horses imported from Serbia were detected in France and Italy.

KEY WORDS : trichinellosis, prevalence, Serbia.

T Trichinellosis is the most serious problem of all the food borne parasitic diseases in Serbia in the last decades. For the first time it was detected in pigs at the beginning of the previous century when large quantities of live swine were exported to Germany, where trichinoscopy of pork was obligatory even then. Meat inspectors in Berlin detected Trichinella spiralis infection in $0.11 \%$ carcasses from pigs imported from Serbia (Djordjevic, 1989). The first outbreak of human trichinellosis in Serbia was described at Zemun hospital in 1923. Veterinary inspection of pork for public use is obligatory since 1952 .

The number of infected pigs before World War II was high, but exact figures are not available. However, the reported number of infected humans was much lower before the World War II, possibly due to the better recognition of the human trichinellosis in last decades.

\footnotetext{
* Institute for the Application of Nuclear Energy (INEP), Banatska 31b, 11080 Belgrade, Yugoslavia.

** Institute for Meat Technology and Hygiene, Kacanskog 13, 11000 Beograd, Yugoslavia.

Correspondence: K. Cuperlovic.

Tel.: 38111671067 - e-mail: mculf@nbnet.nb.ca
}

\section{EPIZOOTIOLOGY AND EPIDEMIOLOGY OF TRICHINELLOSIS}

hrough the systematic epizootiological investigations of trichinellosis, carried out in former Yugoslavia for the first time from 1980-1990 as part of the YU-USDA project, three endemic regions were found in Serbia (Srem, Macva, Negotinska Krajina) and one in Croatia (Slavonija) (Cuperlovic, 1995; Djordjevic, 1989; Marinculic et al., 1991). Parasitological and serological studies were performed on 154,853 swine originating from small farms and 202,603 swine originating from industrial farms. From 154,853 swine grown at non-industrial farms, 99 were infected with Trichinella spiralis (the identification of the species was performed in the Istituto Superiore di Sanitá, Roma, Italy). Pigs from industrial farms were not infected with Trichinella spiralis (Djordjevic, 1989). During this period, the artificial digestion method, introduced at the majority of slaughterhouses for routine control, resulted in significant improvement of the parasitological diagnosis (Djordjevic, 1991). These studies and other official sources indicated that the prevalence of trichinellosis among swine, for the 1980-1990 period, was relatively low (less than $0.02 \%$ ).

Registered human trichinellosis, during the same period, was on average 100-200 persons/year, except in 1985, when 684 subjects were reported to have clinical trichinellosis (Timotin, 1986).

Besides humans and swines, in former Yugoslavia as well in Serbia, trichinellosis is described in wild life. Brglez (1988) reported high infection rates in wild boars ( $4.3 \%$ ), bears (16.8\%), foxes $(5,5 \%)$, badgers (25\%) and lynxs (47\%) but high prevalences of trichinellosis in wolfs, wildcats and other mustelids were previously reported.

Horse trichinellosis has not been detected in former Yugoslavia, although $20 \%$ of the exported animals was serologically examined. However, in 1975 and 1984, 102 humans were infected in Italy after consumption of horse meat imported from Yugoslavia.

Between 1991 and 1993 dramatic events took place in former Yugoslavia, which besides many other problems 
and tragedies, resulted in the spread of parasitic infections. Swine trichinellosis spread from previously restricted three endemic regions to almost the whole country, where previously it was rare and sporadic. The prevalence of trichinellosis increased particularly in the province of Srem at the border of Slavonia (Croatia), previously discovered in the US-Yugoslav studies as an endemic area. Then, for the first time, trichinellosis was detected in one industrial farm, while in some non-industrial farms close to the border the prevalence of trichinellosis reached $50 \%$ of the examined swine. Trichinellosis was also found among dog and rats in these farms (Dimitrijevic et al., 1996).

The prevalence of trichinellosis among slaughtered swine detected by parasitological examinations (trichinoscopy or enzymatic digestion) in the last six years (1994-1999) shows that the spreading of trichinellosis was fast and permanent (Table I). The percentage of infected swine reached and passed numbers found at the beginning of the previous century. The number of examined swine carcasses has increased, particularly for swine slaughtered at farms for domestic consumption (Table I). That is of importance for the prevention of human trichinellosis, established mostly after the consumption of non-inspected or nonregularly inspected pork or meat products like sausages.

The occurrence of trichinellosis in human for the period 1994-1999 ranged between 395 cases (1998) and 804 (1997). In 1994, it amounted to 493, in 1995 to 803, in 1996 to 598 and in 1999 to 555 infected individuals. All serologically positive persons with or without clinical signs of the disease were considered as infected. Horse trichinellosis was not detected in carcasses inspected at two specialized slaughterhouses (Vinca, Novi Sad), between 1994 and 1999, even when sample size for the enzymatic digestion method was increased from five to 10 grams of meat. However, in 1998 two outbreaks took place in France with more than 500 humans infected after consumption of horse meat ori- ginating from live horses imported from Yugoslavia, slaughtered in France and meat inspected by their veterinary services.

\section{DISCUSSION}

richinellosis is recognized in Serbia, by professionals and the authorities, as a serious health and animal husbandry problem. Therefore Ministry of Agriculture, Forestry and Water Supply and Ministry of Health of The Republic of Serbia formed in 1990 an advisory board called The Commission for Trichinellosis. The aim of the board is to help veterinary and health services, by the expertise and advice, in the prevention of human infection and eradication of swine trichinellosis. The activities of the Commission could be briefly summarized as follows:

1. To follow epidemiology and epizootiology of trichinellosis in the country and offer professional help to the veterinary and health services.

2. To propose amendments to existing regulations, instructions and directives to authorities, based on country's needs and legislation in the world, primarily that of OIE and EC. At the moment the existing regulations in Serbia fulfill the request for the prevention of human trichinellosis and for the reduction of swine trichinellosis.

3. To stimulate organization of seminars, lectures, symposia and present scientific and professional news in the field of trichinellosis as well as the changes in legislation.

4. To assists the Ministry of Agriculture in the preparation of the Annual program for health protection of domestic animals.

5. To perform regular control of the laboratories engaged in meat inspection and equalizes the applied diagnostic methods in accordance with existing regulations.

\begin{tabular}{|c|c|c|c|c|c|c|}
\hline Year & 1994 & 1995 & 1996 & 1997 & 1998 & 1999 \\
\hline \multicolumn{7}{|c|}{ Number of inspected pigs } \\
\hline At slaughterhouses & $1,270,602$ & $1,395,895$ & $1,554,093$ & $1,723,237$ & $1,442,054$ & $1,200,000$ \\
\hline At farms & 268,549 & 152,713 & 255,377 & 627,452 & 543,029 & 853,782 \\
\hline Total & $1,539,151$ & $1,548,608$ & $1,809,470$ & $2,350,689$ & $1,985,083$ & $2,053,782$ \\
\hline \multicolumn{7}{|c|}{ Number of infected pigs } \\
\hline At slaughterhouses & 441 & 837 & 1,469 & 1,500 & 1,156 & 1,185 \\
\hline At farms & 543 & 490 & 736 & 943 & 1,487 & 2,290 \\
\hline Total & 984 & 1,327 & 2,205 & 2,443 & 2,643 & 3,475 \\
\hline \multicolumn{7}{|c|}{ Prevalence ( $\%$ infections) } \\
\hline At slaughterhouses & 0.03 & 0.06 & 0.09 & 0.09 & 0.08 & 0.10 \\
\hline At farms & 0.20 & 0.32 & 0.29 & 0.15 & 0.27 & 0.27 \\
\hline Total & 0.06 & 0.08 & 0.12 & 0.10 & 0.13 & 0.17 \\
\hline
\end{tabular}

Table I. - Prevalence of the swine Trichinellosis in Serbia for period 1994-1999. 
6. To introduce Quality Assurance System for trichinoscopy, enzymatic digestion method and serology testing of Trichinella infection in human, livestock and game animals.

In spite of the efforts of professionals, trichinellosis in Serbia is spreading in humans presumably as direct consequence of disturbing events over the population in the last years (civil war, brake up of former country, NATO attack, EC sanctions, significant decrease of national income, financial difficulties and others), although many other factors are also present (regulations are not always applied, responsible services and authorities are not coordinated in eradication of trichinellosis, illegal meat turnover, etc.). Control and limitation of these factors could result in the additional prevention of human trichinellosis and significant reduction in the infection of swine.

\section{REFERENCES}

BRGLEZ J. The incidence of trichinellosis in some wild animals in Yugoslavia, in: Trichinellosis. Tanner Ch.E., Martinez-Fernandez A.R. \& Bolas-Fernandez F. (eds). Consejo Superior de Investigaciones Cientficas Press, Madrid, Spain, 1988, 412-415.

CuPERLovic K. Trihineloza ljudi i zivotinja, Medicinska knjiga, Beograd (II izdanje), 1995.

Dimitrijevic S., Sofronic-Milosavljevic Lj. \& Cokic Z. Trichinella spiralis infection in dogs and rats in one endemic district of trichinellosis in Serbia. Abstract of the $7^{\text {th }}$ European Multicolloquium of a Parasitology, Parasitologie, 1996, $38,288$.

DJORDJEVIC M. Rasirenost trihineloze svinja u nekim enzootskim podrucjima Srbije, PhD Thesis, Univerzitet u Beogradu, 1989.

DJORDJEVIC M. Detection of Trichinella by various methods in Yugoslavia. Proc. $33^{\text {rd }}$ SEAMEO-TROPMED Seminar on Emerging Problems in Food-Born Parasitic Zoonosis: Impact on Agriculture and Public Health. Thailand, 1417 November 1990, Southeast Asian J. Trop. Med. Public Health, 1991, 22, 326-328.

Marinculic A., Rapic D., Brglez J., Dzakula N. \& Stojlijkovic K. Epidemiological survey of trichinellosis in Yugoslavia. Proc. $33^{\text {rd }}$ SAEMO-TROPMED Seminar for Emerging Problems in Food-Born Parasitic Zoonosis: Impact on Agriculture and Public Health. Thailand, 14-17 November 1990, Southeast Asian J. Trop. Med. Public Health, 1991, 22, 302307.

TiмотіN M. Naša iskustva na suzbijanju epidemije trihineloze u Sremskoj Mitrovici 1985. Zbornik radova Druge konferencije Drustva sanitarnih tehnicara Jugoslavije, Pula, 1986, 121-123. 